\title{
Xanthomonas campestris pv. campestris Requires a Functional pigB for Epiphytic Survival and Host Infection
}

\author{
A. R. Poplawsky and W. Chun \\ Plant Pathology Division, Department of Plant, Soil and Entomological Sciences, University of Idaho, \\ Moscow 83844-2339, U.S.A. \\ Accepted 26 February 1998.
}

When cauliflower plants (Brassica oleraceae) were misted with bacterial suspensions of Xanthomonas campestris pv. campestris (causal agent of black rot of cruciferous plants), two separate populations of the pathogen were associated with the leaves. Initially, bacteria removable by sonication and sensitive to sodium hypochlorite treatment predominated (easily removable epiphytic bacteria, EREB). However, after 2 weeks, bacteria not removable by sonication and insensitive to sodium hypochlorite treatment were dominant. Although the exact location of this second population of the pathogen was not determined, evidence is presented to support its location in protected sites on the leaf surface. pigB of this pathogen is required for production of extracellular polysaccharide (EPS), xanthomonadin pigments, and the diffusible signal molecule, DF (diffusible factor). DF can extracellularly restore EPS and xanthomonadin production to pigB mutant strains. Parent strain B-24 and pigB mutant strain B24-B2 were identical for in planta growth and symptomatology after artificial infection by injection in leaf mid-veins. Subsequently, $X$. campestris pv. campestris parent strain B-24, Tn3HoHo1 pigB insertion mutation strain B24-B2, chromosomally restored pigB mutation strain B24-B2R, and strain B24-79 with a Tn3HoHo1 insertion in an unrelated part of the genome were compared for epiphytic survival on, and natural infection of, cauliflower. After application, strains B-24, B24-B2R, and B24-79 all maintained leaf EREB populations of between approximately 3 and $6(\log [1+C F U$ per $\mathrm{g}$ of fresh weight]) over a 3-week period, whereas B24-B2 populations fell to nearly undetectable levels. Plants sprayed with strains B-24, B24-B2R, and B24-79 averaged between 1.0 and 1.2 lesions, whereas those sprayed with B24-B2 averaged only 0.03 lesions per plant after 3 weeks. Differences in EREB population levels did not explain the observed differences in host infection frequencies, and the results indicated that strain B24-B2 was reduced in its ability to infect the host via the hydathodes, but unaffected in infection via wounds. When strains B-24 and B24-B2 were mixed in equal numbers and sprayed on plants to-

Corresponding author: A. R. Poplawsky; Department of Plant, Soil and Entomological Sciences, 242 Agricultural Sciences Building, University of Idaho, Moscow 83844-2339 U.S.A.; Telephone: 1-208-885-7020/ 7639; Fax: 1-208-885-7760; E-mail: alpop@uidaho.edu gether, B24-B2 epiphytic populations were intermediate between those of B-24 applied alone and B24-B2 applied alone. These results indicate that a functional pigB is required for epiphytic survival and natural host infection under the experimental conditions tested, and suggest that DF, xanthomonadins, and EPS could all be important for survival of this pathogen on the leaf surface, and/or for host infection.

Xanthomonas bacteria are the causal agents of disease on at least 124 monocot and 268 dicot plant hosts (Leyns et al. 1984). These bacteria are known for their mucoid, yellowpigmented appearance, and many of them can survive and multiply as epiphytes (Starr 1981; Hirano and Upper 1983). Xanthomonadins are yellow, membrane-bound, brominated aryl-polyene pigments of uncertain function and unique to the genus Xanthomonas (Starr 1981). In one study, production of these pigments and protection against photobiological damage were associated (Jenkins and Starr 1982). The production of extracellular polysaccharide (EPS; responsible for mucoidy) is related to virulence in other phytopathogenic bacteria (Coplin and Cook 1990; Cook and Sequeira 1991; Kao et al. 1992), and may also be important for tolerance to desiccation (Wilkinson 1958; Roberson and Firestone 1992). An association between EPS production and virulence has been widely reported in X. campestris (Corey and Starr 1957; Sutton and Williams 1970a, 1970b; Daniels et al. 1984; Shaw et al. 1988).

In previous work, we identified an 18.6-kbp genomic region from $X$. campestris pv. campestris (pig) that contained seven transcriptional units involved in xanthomonadin production (Poplawsky et. al 1993; Poplawsky and Chun 1997a). Insertional inactivation of one of these transcriptional units, pigB, resulted in 82 and $73 \%$ reductions in xanthomonadin and EPS production levels, respectively (Poplawsky and Chun 1997a). Most of the strains of Xanthomonas tested produced a diffusible factor (DF) that could extracellularly restore pigB mutant strains to normal xanthomonadin and EPS production. DF had the properties of a pheromone (Chun et al. 1997), and a functional pigB was required for its production (Poplawsky and Chun 1997a). With artificial infection (syringe and needle inoculations into leaf mid-veins) pig $B$ mutant strains were identical to the parent strain in plant symptomatology (Poplawsky 
and Chun 1997a). pigB is approximately $2.3 \mathrm{~kb}$ in size and probably encodes multiple products (Poplawsky and Chun 1997a). Partial DNA sequencing suggests that the product of the open reading frame ORF 1 has a regulatory role (Poplawsky and Chun 1997b).

The vast majority of research concerning the interaction between phytopathogenic xanthomonads and their hosts has focused on the pathogenic interaction that occurs after entry of the pathogen into the host. These studies have identified several pathogenicity, virulence, and host-specificity genes (for review see Keen et al. 1993). However, other stages of phytopathogenic bacterial development are important to the establishment of disease. In particular, epiphytic development prior to the entry of a bacterial pathogen into the host may be a prerequisite to plant infection and disease development (for reviews see Leben 1981; Hirano and Upper 1983). Natural infection of cruciferous hosts by $X$. campestris pv. campestris occurs through wounds or the hydathodes at the margins of host plant leaves (Russell 1898; Cook et al. 1952). This vascular pathogen then forms characteristic, V-shaped lesions emanating from the margins of the leaves. We reasoned that since xanthomonadins may be important for protection against photo-biological damage, and EPS may have a role in protection against desiccation, these two bacterial products could be important for survival of the pathogen on the leaf surface. Since a functional pigB is required for the production of EPS and xanthomonadins, we reasoned that pig $B$ might be crucial for epiphytic survival and host plant infection. The following study tests this hypothesis.

\section{RESULTS}

\section{Strain development and characterization.}

Twelve pigmented, mucoid, ampicillin-sensitive, tetracycline-sensitive strains were isolated from continuous culture of B24-B2(pIG102) under conditions that were nonselective for the retention of pIG102. No pigmented strains were obtained from the simultaneous experiment conducted with strain B24-B2. When subjected to Southern hybridization with pIG102 as a probe, these 12 strains all showed the DNA rearrangement expected for replacement of the genomic, mutant $\operatorname{pig} B$ region with the plasmid-borne, unaltered $\operatorname{pig} B$ region (data not shown). One of these isolates was selected and designated B24-B2R.

Parent strain B-24, mutant strain B24-79 (a strain with a Tn3HoHol insertion in an unrelated part of the genome), and restored pigB mutant strain B24-B2R all had similar levels of EPS and pigment production, whereas the $\operatorname{pig} B$ mutant strain B24-B2 had xanthomonadin levels that were approximately $10 \%$ and EPS levels that were approximately $7 \%$ of those observed with the other strains (Table 1). Similar levels of DF production were detected from the first three strains, and no DF production was detected from B24-B2.

Recovery of strains B-24 and B24-B2 on a rich medium (NSA) was compared with recovery on the semi-selective medium, FS(M). Recovery of both strains on FS(M) medium was greater than $94 \%$ of that observed on NSA medium.

\section{Epiphytic survival and disease development.}

In preliminary experiments with strains B-24 and B24-B2, treatment of leaves with sodium hypochlorite was shown to have no effect on internal numbers of the pathogen after syringe inoculations in leaf mid-veins (data not shown). Sodium hypochlorite treatment of leaves at 1 day or 1 week after misting with bacterial suspensions eliminated approximately 99.5 or $75 \%$, respectively, of the bacteria that could be detected by sonication of the leaves.

Initially, it was of interest to determine the sizes and locations of different pathogen populations after spraying cauliflower plants with bacterial suspensions, and incubation of plants at $28^{\circ} \mathrm{C}$ and 40 to $50 \%$ relative humidity (RH). We found that strain B-24 bacteria removable by sonication (easily removable epiphytic bacteria, EREB) predominated at week 0 (Fig. 1A). However, a second population of the pathogen that was not removable by sonication steadily gained prominence during the 3 -week period thereafter. After 3 weeks it represented $99 \%$ or greater of the total pathogen numbers, and was unaffected by treatment of the leaves with sodium hypochlorite. In the same experiment, strain B24-B2 also developed two similar pathogen populations (Fig. 1B), although at weeks 2 and 3 the numbers of both were, respectively, approximately 10- to 50-fold and 60- to 500-fold lower than those of strain B-24. Occasional, small, black rot lesions were first noticed at the margins of leaves after 2 weeks, and fully developed, chlorotic lesions with blackened veins became apparent after 3 weeks of incubation. At this time, plants sprayed with strain B-24 averaged 2.82 lesions, whereas those sprayed with A-7 averaged 0.08. This experiment was repeated with similar results (data not shown).

The development of EREB populations of four strains of $X$. campestris pv. campestris was compared after cauliflower plants were sprayed, and incubation at approximately $28^{\circ} \mathrm{C}$ and 40 to $50 \% \mathrm{RH}$. Over a 3-week period, EREB populations of the parent strain B-24 and restored mutant strain B24-B2R stayed close to the starting level $(5.0$ to $6.0, \log [1+\mathrm{CFU} / \mathrm{g}])$, whereas the populations of pigB mutant strain B24-B2 decreased from this level to approximately $1.0(\log [1+\mathrm{CFU} / \mathrm{g}])$ when detectable (Fig. 2A). This experiment was repeated with similar results (data not shown). No populations of the pathogen were ever observed on plants sprayed only with buffer. When B24-79 (a Tn3HoHo1 mutant strain with an insertion in an unrelated part of the genome) was tested, EREB population levels of this strain and B-24 fluctuated between the starting level (approximately 6.0, $\log [1+\mathrm{CFU} / \mathrm{g}])$ and approximately $3.0(\log [1+\mathrm{CFU} / \mathrm{g}])$, (Fig. 2B). EREB population levels of strain B24-B2 were essentially undetectable. This experiment was also repeated with similar results (data not shown).

Table 1. Characterization of four strains of Xanthomonas campestris pv. campestris

\begin{tabular}{lccc}
\hline Strain & Xanthomonadins $^{\mathbf{w}}$ & $\begin{array}{c}\text { EPS } \\
(\mathbf{m g} / \mathbf{m l})^{\mathbf{x}}\end{array}$ & DF $^{\mathbf{y}}$ \\
\hline B-24 (parent) & $0.476 \mathrm{a}^{\mathrm{z}}$ & $3.06 \mathrm{a}$ & + \\
B24-B2 (pigB mutant) & $0.048 \mathrm{~b}$ & $0.21 \mathrm{~b}$ & - \\
B24-B2R (restored mutant) & $0.461 \mathrm{a}$ & $2.63 \mathrm{a}$ & + \\
B24-79 (unrelated mutant) & $0.462 \mathrm{a}$ & $2.91 \mathrm{a}$ & + \\
\hline
\end{tabular}

${ }^{\mathrm{w}}$ Absorbance at $441 \mathrm{~nm}$ of boiled methanol extracts.

${ }^{x}$ Extracellular polysaccharide, quantified with Anthrone reagent.

y Diffusible factor.

${ }^{\mathrm{z}}$ Values are averages of two replicates. Values in each column followed by different letters were statistically different: $\operatorname{LSD}(0.05)=0.03$ for xanthomonadins, and 0.50 for EPS. 
In the above experiments, typical black rot lesions were observed originating at the margins of leaves after 2 to 3 weeks. Treatment of plants with strains B-24, B24-B2R, and B24-79 resulted in approximately 1.0 to 1.2 black rot lesions per plant after 3 weeks (Table 2). However, only one, small, black rot lesion was observed in all of the plants sprayed with strain B24-B2 (0.03 lesions per plant). When this diseased tissue was macerated and dilutions were plated on FS(M) medium, only Xanthomonas bacteria typical of strain B24-B2 (nonmucoid, nonpigmented, and $\mathrm{Ap}^{\mathrm{r}}$ ) were recovered.

Incubation of plants at $95 \% \mathrm{RH}$ instead of 40 to $50 \% \mathrm{RH}$ allowed for increased EREB population levels of X. campestris pv. campestris (Fig. 3). Strain B-24 EREB population levels increased approximately 10- to 100-fold, whereas B24-B2 levels decreased 10- to 100-fold during the 3-week period. After 3 weeks, plants sprayed with strain B-24 averaged 1.00 lesions, and those sprayed with strain B24-B2 averaged 0.04 lesions (Table 2). This experiment was repeated with similar results (data not shown).

Since lesion numbers were normally distributed (data not shown) and bacterial epiphytic populations are lognormally distributed (Hirano et al. 1982), a Pearson's one-tailed correlation analysis for normally distributed variables was performed on the number of black rot lesions observed at 3 weeks, and EREB population levels $(\log [1+\mathrm{CFU} / \mathrm{g}])$ of all of the strains in the above described experiments. Correlations at $16 \mathrm{~h}$ and at 1,2 , and 3 weeks were $0.07,0.45,0.47$, and 0.56 , respectively, and none of these was significant.
When parent strain B-24 and pigB mutant strain B24-B2 were mixed in equal numbers and sprayed on cauliflower plants that were then incubated at $28^{\circ} \mathrm{C}$ and 40 to $50 \% \mathrm{RH}$, $\mathrm{B} 24-\mathrm{B} 2$ population levels were intermediate between the levels of B24-B2 inoculated alone and B-24 inoculated alone at weeks 1 and 2, but then fell to levels close to those of B24-B2 inoculated alone at week 3 (Fig. 4). Strain B-24 population levels from the mixed applications were nearly identical to those of B24-B2 from the mixed applications until week 3, when they climbed to a level similar to that of B-24 inoculated alone. Similar results were obtained when this experiment was repeated (data not shown). Lesion numbers could not be assessed, since lesions caused by strains B-24 and those caused by strain B24-B2 were not distinguishable.

\section{In planta growth and symptomatology.}

After artificial inoculation into leaf mid-veins by injection, bacterial numbers in planta increased from approximately 3 to approximately $10(\log [1+\mathrm{CFU} / \mathrm{g}])$ over a 6-day period (Fig. 5 ). The in planta growth characteristics of parent strain B-24 and mutant strain B24-B2 were nearly identical. The symptomatology of these two strains was also nearly identical, with approximately $65 \%$ of inoculated leaves exhibiting black rot symptoms (chlorosis, vein blackening, and wilting) at 6 days after inoculation, and $90 \%$ of the leaves exhibiting symptoms after 8 days. This experiment was repeated with similar results. Alternatively, each of these two strains was sprayinoculated onto 36 plants, each with one leaf wounded at the margin. After 2 weeks, lesions had developed at 25 and $17 \%$
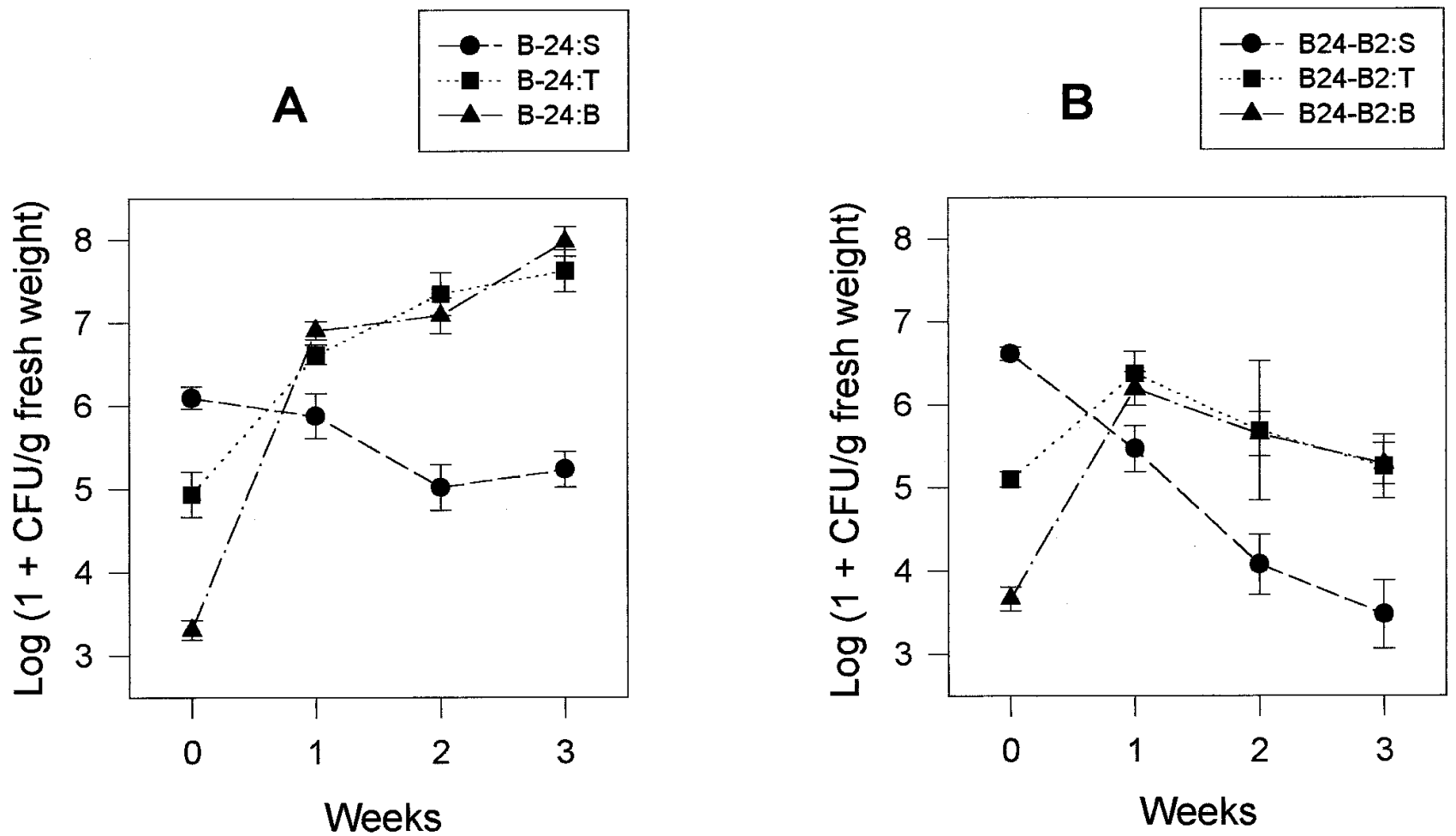

Fig. 1. A, Bacterial populations of Xanthomonas campestris pv. campestris parent strain B-24. B, pigB Tn3HoHo1 insertion mutation strain B24-B2. Both associated with cauliflower leaves after spraying with bacterial suspensions and incubation at 40 to $50 \%$ relative humidity. Suffix "S" refers to populations removed by sonication; suffix " $\mathrm{T}$ " refers to populations remaining after sonication; suffix "B" refers to populations remaining after sonication and treatment with sodium hypochlorite. Each data point is the mean of eight replicates. Bars at each point represent the standard error of the mean. 
of the wound sites on plants sprayed with B-24 and B24-B2 suspensions, respectively, and these infection frequencies were not significantly different based on an $F$ test $(P=0.10)$. However, in this same experiment, infection frequencies of 0.917 and 0.028 lesions per plant were observed at leaf margin, nonwound sites for plants sprayed with strain B-24 and B24-B2 suspensions, respectively, and these infection frequencies were significantly different based on an $F$ test $(P=$ $0.005)$. This experiment was repeated with similar results. In general, the lesions observed at wound sites were much larger and more highly developed than those at nonwound sites. After 3 weeks, many of the wounded, black-rot-infected leaves were completely senescent; thus, the numbers of lesions could not be enumerated reliably.

\section{DISCUSSION}

Although the phytopathogenic xanthomonads are not well characterized with respect to epiphytic survival, the few existing studies support the idea that the epiphytic phase is important in the disease cycle of these pathogens (Leben 1963; Cafati and Saettler 1980a, 1980b; Kuan et al. 1986; Timmer et al. 1987; Azad and Schaad 1988). In all of these studies, leaves were either washed or sonicated, or symptomless leaves were homogenized, and the resulting numbers were considered the surface or epiphytic populations of the pathogens.
In this study, we present evidence for two populations of the pathogen after spraying leaves with bacterial suspensions. Initially, bacteria removable by sonication predominated. However, by week 2 bacteria not removable by sonication, and not affected by treatment with sodium hypochlorite, predominated. These bacteria were detected by homogenization of leaves, thus we cannot be sure whether they were internal, or in "protected sites" on the leaf surface. Previous reports have suggested the presence of bacteria in protected sites on the leaf surface (Haefele and Lindow 1987; Beattie and Lindow 1994), and for two reasons it is likely that at least some of the bacteria in our study were in similar sites. First, they were detected at only $16 \mathrm{~h}$ after leaves were sprayed. It is unlikely that infection and significant bacterial growth in planta (an increase to 3 to $5, \log [1+\mathrm{CFU} / \mathrm{g}]$ ) would have occurred in this short period of time. If this were the case, one would expect to have seen symptom development after 1 week, instead of the observed 2 to 3 weeks (see Figure 5). Second, these bacterial populations were detected with strain B24-B2 also, and since this mutant strain infected the host plant only very rarely $(0.08$ lesions per plant $=1.0$ lesion per 25 leaves sampled), internal bacteria could not have accounted for the population levels observed. The levels of both bacterial populations were reduced with mutant strain B24-B2, compared with the parent strain B-24. In preliminary experiments, treatment with sodium hypochlorite had no effect on the pathogen in planta; thus, this treatment only affected epiphytic
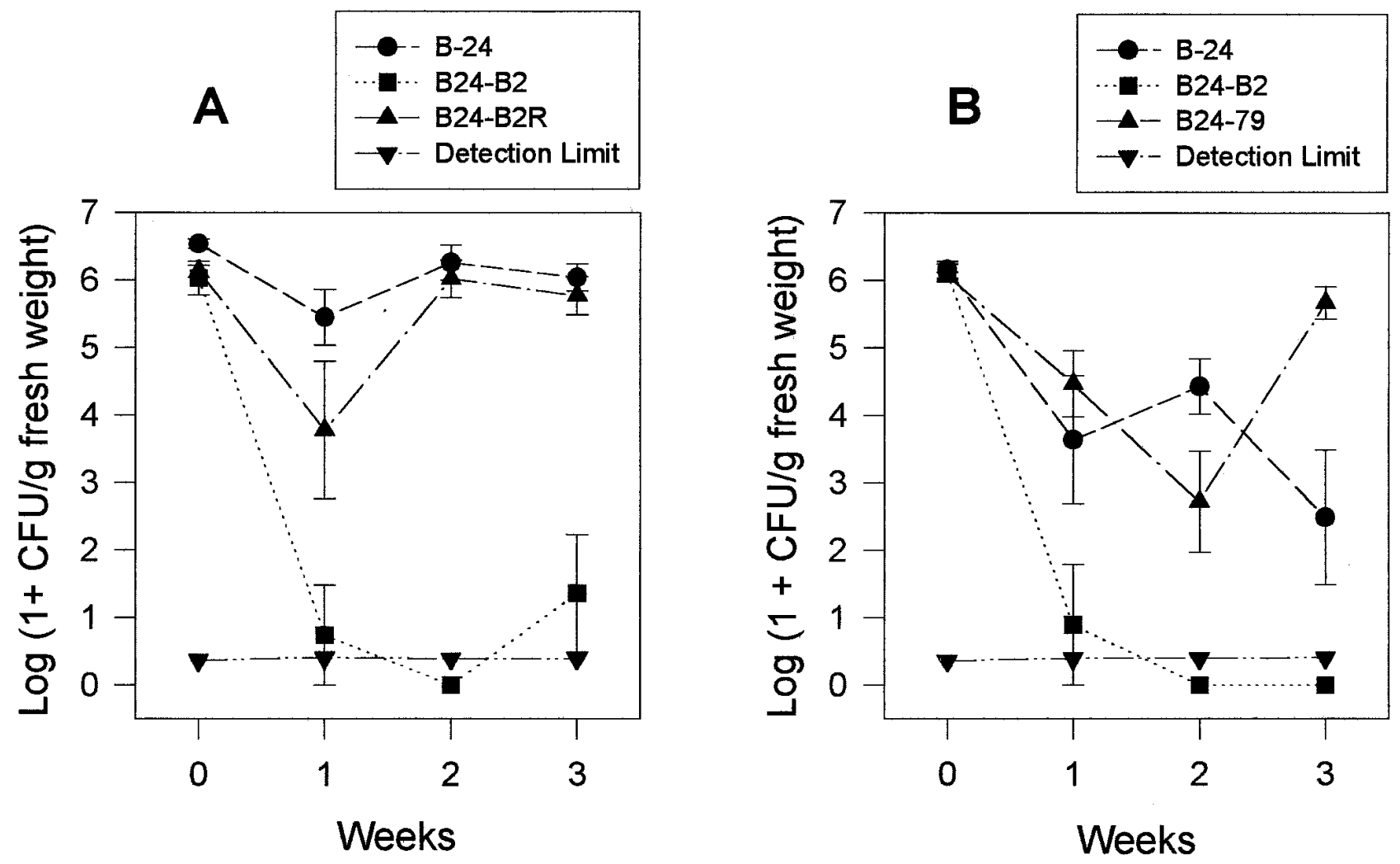

Fig. 2. Epiphytic (EREB) populations of (A) Xanthomonas campestris pv. campestris parent strain B-24, pigB Tn3HoHo1 insertion mutation strain B24$\mathrm{B} 2$, and chromosomally restored pigB mutant strain B24-B2R; (B) parent strain B-24, pigB Tn3HoHo1 insertion mutation strain B24-B2, and unrelated Tn3HoHo1 insertion mutation strain B24-79 detected on cauliflower plants incubated at 40 to $50 \%$ relative humidity. Each data point is the mean of five replicates. Bars at each point represent the standard error of the mean. 
bacteria. Also, since most of the bacteria removable by sonication could not be recovered by sonication after sodium hypochlorite treatment, we conclude that the bacteria removable by sonication were epiphytic. Since we could be sure of the location of only those bacteria removable by sonication, all further experiments were conducted with sonication, and the bacterial populations detected were referred to as easily removable epiphytic bacteria (EREB).

We found that $X$. campestris pv. campestris parent and chromosomally restored pigB mutant strains maintained high EREB populations, and infected plants at about the same frequency. The EREB population levels of the pigB, single-site insertion mutation strain fell to undetectable or nearly undetectable levels, and the infection frequency was only about $3 \%$ of that of the other strains. Reductions in EREB population levels and host infection were not simply due to the insertion of Tn3HoHol in the bacterial genome, since strain B24-79 had EREB population levels and host infection comparable to those of the parent strain, B-24. Thus, a functional pigB is required for the maintenance of EREB populations of this pathogen, and also for host infection. Since in the initial experiments (Fig. 1), the levels of the second, unidentified population of the pathogen varied proportionally with the EREB population levels, it is likely that a functional $\operatorname{pig} B$ is required for all epiphytic populations of the pathogen. Reductions in EREB populations of strain B24-B2 were not as great in these experiments as in the experiments in which EREB populations of all four strains of $X$. campestris pv. campestris were monitored (Fig. 2). Although we cannot be sure of the reason for this, the higher starting level of strain B24-B2 in the first experiment (approximately 6.7, $\log [1+\mathrm{CFU} / \mathrm{g}]$ ), compared with that in the later experiments (approximately 6.0, log $[1+\mathrm{CFU} / \mathrm{g}]$ ) may have contributed to this difference.

These results contribute to what little is known about bacterial epiphytic fitness. Lindow (1991) suggested many "hypothetical" epiphytic fitness traits such as EPS production, tolerance to UV irradiation, motility, catabolic properties, and others. However, only in the case of motility is there evidence for a contribution to epiphytic fitness (Haefele and Lindow 1987). Our work shows that a functional pigB is specifically required for a high level of epiphytic fitness of $X$. campestris pv. campestris under conditions of moderate or low stress. Since pigB is needed for the production of DF, EPS, and xanthomonadins, these results suggest that all three of these bacterial products may contribute to epiphytic fitness. The possibility that xanthomonadins may be important for epiphytic survival is not surprising considering that these pigments may be involved in

Table 2. Average number of lesions observed on plants 3 weeks after application of Xanthomonas campestris pv. campestris

\begin{tabular}{lcc}
\hline & \multicolumn{2}{c}{ Lesions per plant $^{\mathbf{y}}$} \\
\cline { 2 - 3 } Strain & $\mathbf{4 0 \%} \mathbf{R H}$ & $\mathbf{9 5 \%} \mathbf{R H}$ \\
\hline B-24 (parent) & $1.16 \mathrm{a}$ & $1.00 \mathrm{a}$ \\
B24-B2 (pigB mutant) & $0.03 \mathrm{~b}$ & $0.04 \mathrm{~b}$ \\
B24-B2R (restored mutant) & $1.03 \mathrm{a}$ & $\mathrm{NT}^{\mathrm{z}}$ \\
B24-79 (unrelated mutant) & $0.97 \mathrm{a}$ & $\mathrm{NT}$ \\
\hline
\end{tabular}

${ }^{y}$ At two levels of relative humidity (RH). Each value represents the average number of lesions observed on 25 plants. Values followed by different letters were significantly different: $\operatorname{LSD}(0.05)=0.64$.

${ }^{\mathrm{z}}$ Not tested. protection against photobiological damage (Jenkins and Starr 1982), and there is evidence that Erwinia herbicola carotenoid pigments can protect Escherichia coli from damage due to UV irradiation (Gibbins and Peterson 1978, Tuveson et al. 1988). But the suggestion that EPS is an epiphytic fitness factor in $X$. campestris pv. campestris is more controversial, considering the preponderance of evidence for EPS as a virulence factor (Corey and Starr 1957; Sutton and Williams 1970a, 1970b; Daniels et al. 1984; Shaw et al. 1988), and that efforts to tie EPS to epiphytic fitness with Pseudomonas syringae have not been successful (Lindow 1991). However, EPS may function in different capacities during both the epiphytic phase and the pathogenic phase, and we may have observed effects due to the loss of multiple epiphytic fitness factors that might not be observed with the loss of just a single factor. Since EPS is thought to confer tolerance to desiccation, our observation of increased epiphytic survival of strain B24-B2 under conducive conditions (95\% RH), compared with moderately restrictive conditions (40 to $50 \% \mathrm{RH}$ ), is consistent with the idea that EPS production could contribute to epiphytic fitness. If EPS is both a virulence factor and an epiphytic fitness factor in this pathogen, then one might expect two regulatory circuits, one for the regulation of EPS production as an epiphyte, and one for the regulation of EPS production as a pathogen. Indeed, a regulatory system for pathogenicity factors (including EPS) in $X$. campestris pv. campestris is being studied (Tang et al. 1991; Barber et al. 1996), and the diffusible signal component of this system (DSF) is functionally and biochemically different from DF (Poplawsky et al. 1998).

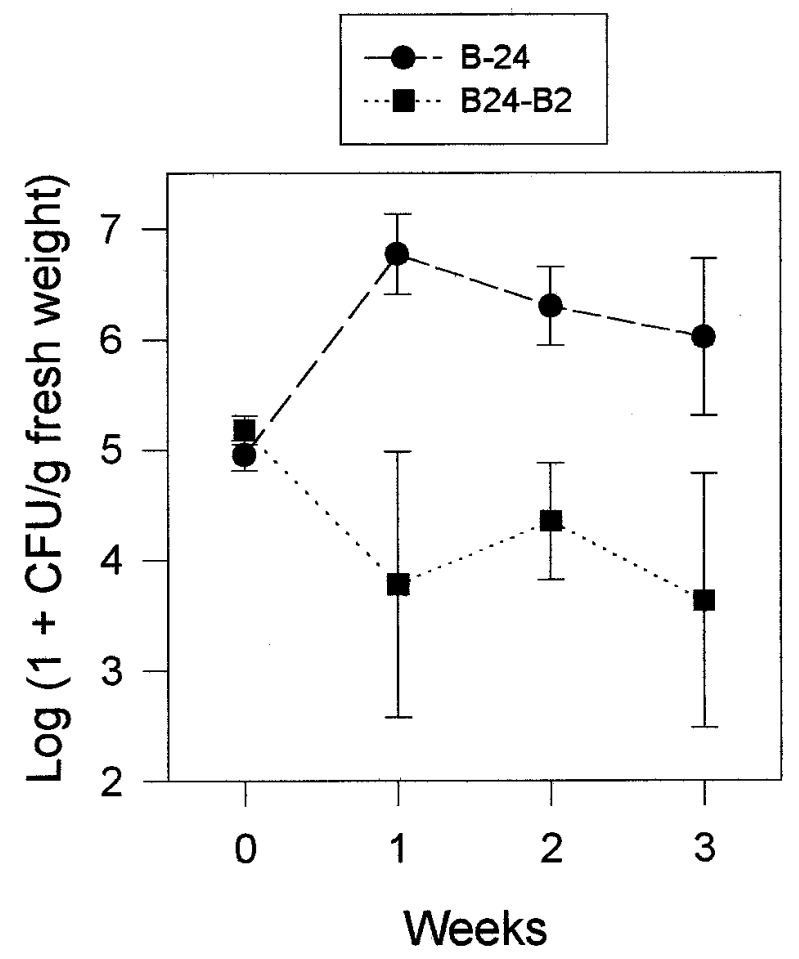

Fig. 3. Epiphytic (EREB) populations of Xanthomonas campestris pv. campestris parent strain B-24 and pigB mutant strain B24-B2 detected on cauliflower plants incubated at $95 \%$ relative humidity. Each data point is the mean of five replicates. Bars at each point represent the standard error of the mean. 
Although bacterial pheromones have been implicated in the control of virulence or pathogenicity in a number of phytopathogenic bacteria (Jones et al. 1993; Pirhonen et al. 1993; Clough et al. 1994; Beck von Bodman and Farrand 1995), this is the first example of a bacterial pheromone that may be involved in epiphytic survival or host plant infection. The partial restoration of the epiphytic fitness of the pigB mutant strain by co-inoculation with the parent strain B-24 is consistent with a role for DF in epiphytic survival. Production of DF by B-24 may extracellularly restore the pigB mutant on the leaf surface. Extracellular complementation could also explain the isolation of naturally occurring $p i g B$ mutant strains from seed (Poplawsky and Chun 1995, 1997a), since pigmented $\mathrm{DF}^{+}$ strains were also isolated from this seed lot (A. R. Poplawsky, unpublished results). However, there are alternative explanations for these observations. Strain B-24 might establish a favorable micro-habitat on the leaf through production of EPS or other DF-controlled products, which might then be available for occupation by strain B24-B2. But, since coapplication of partially purified DF with strain B24-B2 also partially restored the epiphytic fitness of this strain (Chun et al. 1997), the explanation of extracellular complementation on the leaf surface seems most likely.

The simplest explanation for the reduced infection frequencies observed with mutant strain B24-B2 is that reduced epiphytic survival of this strain resulted in reduced infection. For

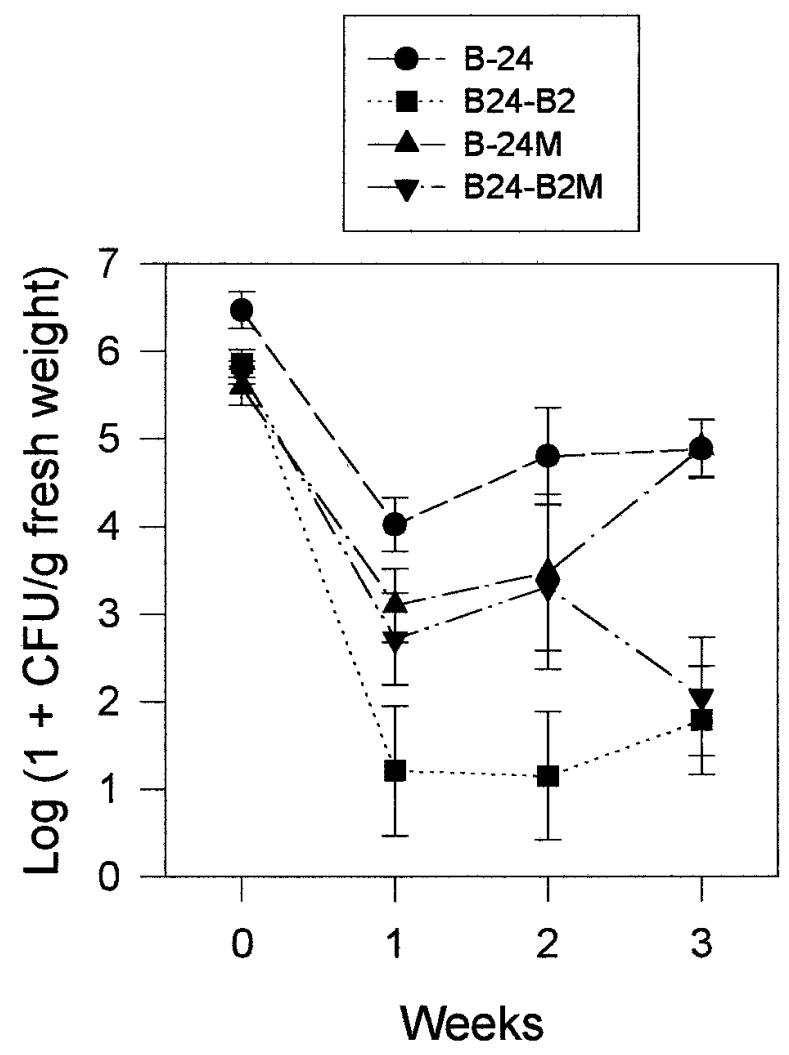

Fig. 4. Epiphytic (EREB) populations of Xanthomonas campestris pv. campestris parent strain B-24, pigB mutant strain B24-B2, and these two strains when mixed together in equal numbers (suffix $M$ ), detected on cauliflower plants incubated at 40 to $50 \%$ relative humidity. Each data point is the mean of five replicates.Bars at each point represent the standard error of the mean. a number of reasons, this is probably not the case. Previous investigators have concluded that $X$. campestris pv. campestris infects via wounds or the hydathodes found on the margins of the host leaves (Russell 1898; Cook et al. 1952; Bretschneider et al. 1989). In extensive studies, infection was never observed via stomata under natural conditions, and it was concluded that a continuous layer of liquid was required for infection at the hydathodes (Cook et al. 1952). In this investigation, it is likely that the infection we observed at nonwound sites was via the hydathodes, since the observed lesions originated at the margins of the leaves, and we took care to use plants without prior wound damage. Additionally, it is likely that infection occurred during the $16-\mathrm{h}$ period after leaves were sprayed with bacterial suspensions, when the plants were incubated in a dew chamber where continuous leaf wetness and hydathode exudation droplets were maintained. Neither leaf wetness nor exudation droplets were ever observed during the subsequent incubation of plants at 40 to $50 \% \mathrm{RH}$ for the following 3 weeks. Our observations of black rot lesions 2 weeks after plants were sprayed with bacterial suspensions is consistent with prior observations of disease following hydathode infection (Cook et al. 1952; Staub and Williams 1972). Since symptoms were observed in our experiments with artificial inoculation approximately 1 week after injection, natural infection could not have occurred later than 1 week after plants were sprayed with bacterial suspensions.

Thus, if reduced epiphytic populations were the reason for the B24-B2 reduced infection frequency, one would expect
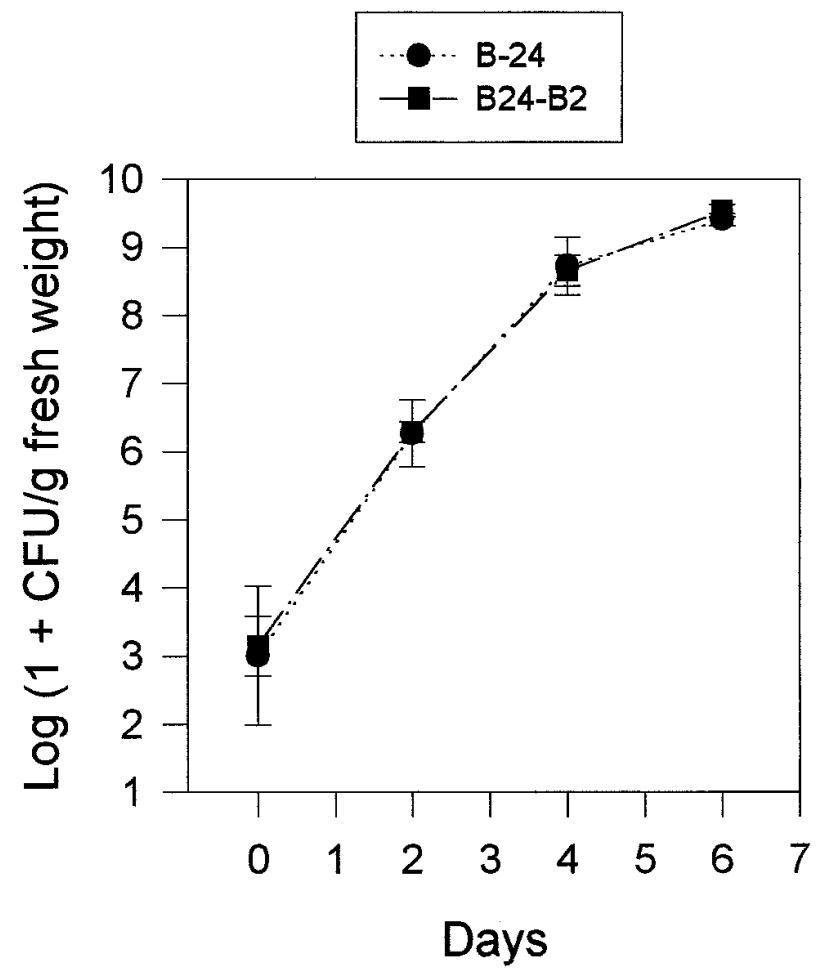

Fig. 5. Growth in planta of Xanthomonas campestris pv. campestris parent strain B-24 and pigB mutant strain B24-B2. Each data point is the mean of four replicates. Bars at each point represent the standard error of the mean. After 7 days, black rot symptoms included extensive chlorosis, blackened veins, and wilting for both strains. 
to see these population reductions at the sampling periods $16 \mathrm{~h}$ or 1 week after plants were sprayed. However, there was not a significant correlation between EREB populations levels and infection frequencies at these or at any other time periods. Additionally, in one experiment, the levels of both populations of strain B-24 were very similar to those of B24-B2 after either 16 $\mathrm{h}$ or 1 week (see Figure 1), yet the B24-B2 infection frequency was only approximately $3 \%$ of the B-24 frequency. Also, EREB populations of both strains B-24 and B24-B2 were greatly increased under conducive conditions (95\% RH; see Figure 3), compared with moderately stressful conditions $(40 \% \mathrm{RH}$; see Figure 2). Yet the infection frequencies of both strains were unaffected by these increased EREB population levels. Finally, in experiments with natural infection via the spraying of bacterial suspensions onto wounded leaves, although plants sprayed with strain B-24 developed a 33-fold greater number of lesions at nonwound sites than plants sprayed with strain B24-B2, the frequencies of infection of these two strains at wound sites were very similar. If the reduction in infection frequency of strain B24-B2 at nonwound sites were simply due to reduced levels of epiphytic bacteria, one would expect to have seen this same reduction in infection at wound sites.

If the difference in infection frequencies between strains B-24 and B24-B2 was not simply the result of differences in epiphytic population levels, then it must have been the result of a difference in the behavior of the two strains during infection. This difference was not a result of behavioral or growth differences after entry into the host, since the two strains showed nearly identical growth characteristics and symptomatology in planta after artificial infection. The difference in infection frequency of these two strains was not due to a difference in the general movement of the bacteria on the leaf surface to the infection point, since if this were the case one would expect to have seen a difference in the frequencies of infection of strains B-24 and B24-B2 at the leaf margin wound sites, as well as the nonwound sites. Assuming that most of the infection at nonwound sites was via the hydathodes (as discussed above), the difference in behavior between these two strains was directly related to entry via the hydathodes. These results indicate that there may be a specific infection process that takes place via the hydathodes and does not occur during infection at wound sites. This is consistent with our observation that lesions at wound sites were much larger than those at nonwound sites after 2 weeks. The postulated specific infection process at hydathodes may require more time than the opportunistic infection at wound sites. Strain B24-B2 may be in some way compromised in this specific infection process, perhaps in its ability to congregate at, or actually enter, the hydathodes. This evidence for a hydathode-specific infection process is of particular interest, since f-gene resistance to black rot in cabbage is fully and rapidly expressed only when the bacteria enter via the hydathodes, as opposed to entry via wounds (Staub and Williams 1972).

The possibility of xanthomonadins, EPS, DF pheromone, or other pheromone-controlled products playing a direct role in bacterial host plant infection via natural openings is completely unexplored, and should provide a fertile field for future research.

\section{MATERIALS AND METHODS}

\section{Bacterial strains and culture.}

E. coli strains used in this study were TB1 and HB101 (Yanisch-Perron et al. 1985). Plasmid pRK2013 (Ditta et al. 1980) was used as a helper plasmid in the bacterial matings. Strain B-24 is a pathogenic, cephalexin-resistant, wild-type strain of $X$. campestris pv. campestris that was previously used to clone and characterize the xanthomonadin encoding region (pig) (Poplawsky et al. 1993; Poplawsky and Chun 1997a). pIG102 (tetracycline-resistant) is a pLAFR3 cosmid clone of the entire pig region that includes pigB (Poplawsky et al. 1993). Strains B24-B2 and B24-79 are derivatives of strain B-24 with Tn3HoHol insertions in pigB and a genomic region to the right of pig, respectively (Poplawsky and Chun 1997a; Fig. 6). Tn $3 \mathrm{HoHol}$ is a derivative of the transposon Tn 3 with a promoter-less $\beta$-galactosidase gene and a disarmed transposase gene (Stachel et al. 1985). This transposon can be used to inactivate and simultaneously construct transcriptional fusions with target genes.

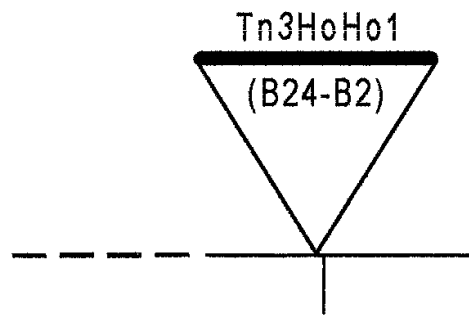

(2.6)

$\mathrm{Sa}$

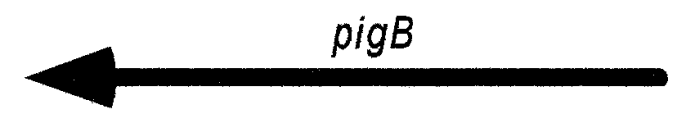

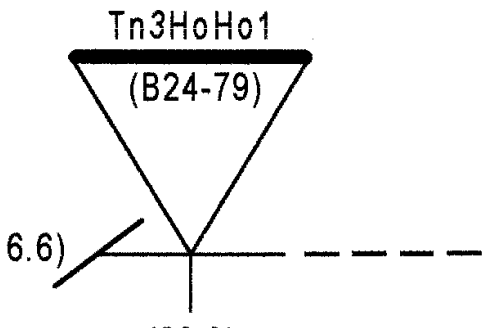

(22.3) 79. Numbers represent distances in kilobase pairs from the left border of pig (see Poplawsky and Chun 1997a). Abbreviations of restriction endonuclease sites are as follows: Sa, SalI; Sm, SmaI; X, XhoI, and E, EcoRI. 
Xanthomonas strains were grown at $28^{\circ} \mathrm{C}$ in nutrient yeast glycerol (NYGB) medium (Turner et al. 1984), nutrient starch agar (NSA) medium (Schaad and Kendrick 1975), or minimal medium (Chatterjee 1980) supplemented with $1 \mathrm{mg}$ of methionine per liter (MAKC). E. coli was grown at $37^{\circ} \mathrm{C}$ in Luria Bertani (LB) medium (Davis et al. 1980). Antibiotics were added to the medium when appropriate at the following concentrations: kanamycin $(\mathrm{Km}), 50 \mathrm{mg} / \mathrm{liter}$; tetracycline $(\mathrm{Tc})$, $12 \mathrm{mg} / \mathrm{liter}$; cephalexin (Ce) and ampicillin (Ap), each at 50 $\mathrm{mg} / \mathrm{liter}$.

\section{Biochemical, molecular, and genetic techniques.}

Previously described methods were used for conjugal plasmid transfer and xanthomonadin quantification (Poplawsky et al. 1993) and Southern hybridization (Poplawsky and Chun 1995), as well as EPS quantification and determination of DF production (Poplawsky and Chun 1997a). Chromosomally restored pig $B$ mutant strains were selected in the following manner. The pig region-encoding cosmid pIG102 was transferred to the pigB mutant strain B24-B2, and a single, pigmented transconjugant was selected and purified (B24B2[pIG102]). This strain was grown for three cycles on NSA(Tc) agar medium, which selected for retention of pIG102 and yellow pigmentation. It was then transferred to continuous NYGB broth culture with no antibiotics for five cycles, at which point the broth culture had turned from yellow to white due to the loss of pIG102. Dilutions were then plated on NSA agar medium with no antibiotics, and occasional yellow pigmented colonies were tested for resistance to tetracycline and ampicillin. Pigmented isolates sensitive to both antibiotics were presumed to be chromosomally restored at $\operatorname{pig} B$. This was verified by Southern hybridization with pIG102 as a probe.

\section{Epiphytic survival and in planta growth.}

Cauliflower plants (variety 3303 from Tanimura \& Antle, Salinas, CA) were germinated in 10.16-cm-diameter, plastic pots in Sunshine Mix \#1 in the greenhouse, thinned to five plants per pot, and treated after 3 weeks with Rapid-Gro fertilizer. The abaxial and adaxial surfaces of leaves from 5- to 6week-old plants were then misted with bacterial suspensions of strains B-24, B24-B2, B24-B2R, or B24-79, or buffer controls. Suspensions were prepared by washing bacteria from 2day-old NSA medium plates with $0.01 \mathrm{M} \mathrm{PO}_{4}$ buffer $(\mathrm{pH} 7.0$, with $0.01 \%$ polyoxyethylene-sorbitan monolaurate [Tween 20] added as a wetting agent), adjusting the turbidity at $A_{600}$ to 1.0 , and diluting 1:1000 in $\mathrm{PO}_{4}$ buffer. This resulted in a bacterial suspension of approximately $10^{7} \mathrm{CFU} / \mathrm{ml}$. Misted plants were left in the dew chamber in the dark for 16 to $20 \mathrm{~h}$, during which leaf wetness was maintained. Plants were subsequently incubated for 3 weeks at 25 to $28^{\circ} \mathrm{C}$ and 40 to $50 \% \mathrm{RH}$ or $95 \%$ RH, with a 16-h photoperiod at an intensity of approximately 4,000 lx. There were five pots per treatment, and pots were arranged in a completely randomized design. Upon transfer to less conducive conditions and each week thereafter, leaves were sampled for populations of the pathogen. A mature but nonsenescent leaf from each pot was selected and removed with the petiole. The leaves were weighed and then submerged individually in $18 \times 150 \mathrm{~mm}$ borosilicate glass culture tubes, each containing $15 \mathrm{ml}$ of $\mathrm{PO}_{4}$ buffer. The end of the petiole was always kept well above the surface of the liq- uid. Between each leaf sampling, all equipment was thoroughly cleaned with $95 \%$ ethanol. When all of the samples from a particular sampling period were collected, the tubes were submerged in a Branson model \#3210 sonicator for 10 min. Subsequently, each tube was vortexed for $5 \mathrm{~s}$ and dilutions $\left(10^{0}, 10^{-1}\right.$, and $\left.10^{-2}\right)$ were plated on FS(M) medium, selective for the pathogen (Schaad 1989). Pathogen numbers were enumerated after 3 to 4 days of incubation at $28^{\circ} \mathrm{C}$. Since epiphytic bacterial populations on leaf surfaces are lognormally distributed (Hirano et al. 1982), data were logtransformed and means and standard errors of the means were then calculated and plotted. Three weeks after the plants were sprayed, the number of typical black rot lesions found originating at the margins of plant leaves was recorded.

In the case of combination treatments with both B-24 and B24-B2, the two strains were mixed in equal numbers to achieve the same inoculum level as described above. Leaf sonicate dilutions were then plated on both FS(M) and FS(M) with ampicillin media. Strain B24-B2 was enumerated on the FS(M)(Ap) medium, and the B-24 population levels were calculated by subtracting the numbers observed on FS(M)(Ap) medium from those observed on FS(M) medium. Strains B-24 and B24-B2 could also be visually differentiated on FS(M) medium due to differences in pigmentation and mucoidy, although this became difficult on plates with greater than approximately 50 colonies. Presumably this difficulty was due to extracellular complementation of B24-B2 colonies by B-24 colonies on the same plates.

Experiments for the comparison of different bacterial populations of the same strain were conducted as described above with some slight differences. In these experiments, two leaves per pot were harvested from eight pots of plants per treatment each week. Leaves from one set were individually sonicated as described above, rinsed in fresh, sterile, phosphate buffer, and then homogenized with a Tissue Tearor (Biospec Products, Racine WI). Dilutions of sonicate solutions and homogenates were plated on FS(M) medium for colony enumeration. Colonies arising from homogenates were considered to be total bacteria remaining after sonication. Total bacteria remaining after sonication and bleach treatment were determined in the same manner as above except that, after sonication, leaves were treated with $0.525 \%$ sodium hypochlorite for $3 \mathrm{~min}$, and then rinsed in excess volumes of distilled water for $5 \mathrm{~min}$, prior to homogenization. Preliminary analysis indicated that log-transformed data more closely approximated a normal distribution than nontransformed data. Thus, log-transformed data were used to calculate and plot means and standard errors of the means.

For in planta growth and assessment of symptomatology, the first true leaves of 4-week-old plants were injected in the mid-vein with fresh bacterial suspensions (approximately $10^{6}$ $\mathrm{CFU} / \mathrm{ml}$ ) of strain B-24 or B24-B2 as previously described (Schaad and Stall 1988). Subsequently for each treatment, $2.54 \mathrm{~cm}^{2}$ leaf sections were removed from four, inoculated, sodium-hypochlorite-treated (as described above) leaves at 2day intervals, weighed, and separately homogenized in phosphate buffer (0.01 M, pH 7.0). These homogenates were then diluted and plated on FS(M) medium. Bacterial numbers were enumerated after 3 to 4 days, and symptomatology was assessed at 6 and 8 days after inoculation. Alternatively, a sterile hole punch was used to make a tiny wound on the terminal 
edge of each leaf, and plants were then sprayed with bacterial suspensions and incubated as described for the epiphytic experiments above $\left(28^{\circ} \mathrm{C}, 40\right.$ to $\left.50 \% \mathrm{RH}\right)$. Lesions at wound sites, and independent of wound sites originating at the margins of leaves, were then enumerated after 2 weeks.

\section{ACKNOWLEDGMENTS}

We acknowledge the technical assistance of Scott Urban, and helpful discussions with G. R. Knudsen. This work was supported in part by grant 9304168 from USDA/NRICGP.

\section{LITERATURE CITED}

Azad, H., and Schaad, N. W. 1988. The relationship of Xanthomonas campestris pv. translucens to frost and the effect of frost on black chaff development in wheat. Phytopathology 78:95-100.

Barber, C. E., Feng, J.-X., Han, B., Slater, H., Tang, J.-L., Wilson, T. J. G., Williams, P., Dow, J. M., and Daniels, M. J. 1996. A novel regulatory system mediated by a small molecule in Xanthomonas campestris. Abstract No. G12 in: Int. Congr. Mol. Plant-Microbe Interact., 8th.

Beattie, G. A., and Lindow, S. E. 1994. Survival, growth, and localization of epiphytic fitness mutants of Pseudomonas syringae on leaves. Appl. Environ. Microbiol. 60:3790-3798.

Beck von Bodman, S. G., and Farrand, S. K. 1995. Capsular polysaccharide biosynthesis and pathogenicity in Erwinia stewartii require in duction by an $N$-acylhomoserine lactone autoinducer. J. Bacteriol. 177:5000-5008.

Bretschneider, K. E, Gonella, M. P., and Robeson, D. J. 1989. A comparative light and electron microscopical study of compatible and incompatible interactions between Xanthomonas campestris pv. campestris and cabbage (Brassica oleracea). Physiol. Mol. Plant Pathol. 34:285-297.

Cafati, C. R., and Saettler A. W. 1980a. Role of nonhost species as alternate inoculum sources of Xanthomonas phaseoli. Plant Dis. 64:194196.

Cafati, C. R., and Saettler, A. W. 1980b. Effect of host on multiplication and distribution of bean common blight bacteria. Phytopathology 70: 675-679.

Chatterjee, A. K. 1980. Acceptance by Erwinia spp. of R plasmid R68.45 and its ability to mobilize the chromosome of Erwinia chrysanthemi. J. Bacteriol. 142:111-119.

Chun, W., Cui, J., and Poplawsky, A. 1997. Purification, characterization, and biological role of a pheromone produced by Xanthomonas campestris pv. campestris. Physiol. Mol. Plant Pathol. 51:1-14

Clough, S. J., Schell, M. A., and Denny, T. P. 1994. Evidence for involvement of a volatile extracellular factor in Pseudomonas solanacearum virulence gene expression. Mol. Plant-Microbe Interact. 7: 621-630.

Cook, A. A., Walker, J. C., and Larson, R. H. 1952. Studies on the disease cycle of black rot of crucifers. Phytopathology 42:162-167.

Cook, D., and Sequeira, L. 1991. Genetic and biochemical characterization of a Pseudomonas solanacearum gene cluster required for extracellular polysaccharide production and for virulence. J. Bacteriol. 173:1654-1662.

Coplin, D. L., and Cook, D. 1990. Molecular genetics of extracellular polysaccharide biosynthesis in vascular phytopathogenic bacteria. Mol. Plant-Microbe Interact. 3:271-279.

Corey, R. R., and Starr, M. P. 1957. Colony types of Xanthomonas phaseoli. J. Bacteriol. 74:137-140.

Daniels, M. J., Barber, C. E., Turner, P. C., Sawczyc, M. K., Byrde, B. W., and Fielding, A. H. 1984. Cloning of genes involved in pathogenicity of Xanthomonas campestris pv. campestris using the broad host range cosmid pLAFR1. EMBO J. 3:3323-3328.

Davis, R. W., Botstein, D., and Roth, J. R. 1980. A Manual for Genetic Engineering: Advanced Bacterial Genetics. Cold Spring Harbor Laboratory, Cold Spring Harbor, New York.

Ditta, G., Stanfield, S., Corbin, D., and Helinski, D. R. 1980. Broad host range DNA cloning system for gram-negative bacteria: Construction of a gene bank of Rhizobium meliloti. Proc. Natl. Acad. Sci. USA 77: $7347-7351$

Gibbins, L. N., and Peterson, D. L. 1978. Responses of Erwinia herbicola Y46 and a non-pigmented mutant to ultraviolet radiation and visible light: survival curves and photoreactivation. Pages 443-450 in: Proc. Int. Conf. Plant Pathogenic Bacteria, 4th.

Haefele, D. M., and Lindow, S. E. 1987. Flagellar motility confers epiphytic fitness advantages upon Pseudomonas syringae. Appl. Environ. Microbiol. 53:2528-2533.

Hirano, S. S., and Upper, C. D. 1983. Ecology and epidemiology of foliar bacterial plant pathogens. Annu. Rev. Phytopathol. 21:243-269.

Hirano, S. S., Nordheim, E. V., Arny, D. C., and Upper, C. D. 1982 Lognormal distribution of epiphytic bacterial populations on leaf surfaces. Appl. Environ. Microbiol. 44:695-700.

Jenkins, C. L., and Starr, M. P. 1982. The brominated aryl-polyene (xanthomonadin) pigments of Xanthomonas juglandis protect against photobiological damage. Curr. Microbiol. 7:323-326.

Jones, S., Yu, B., Bainton, N. J., Birdsall, M., Bycroft, B. W., Chhabra, S. R., Cox, A. J. R., Golby, P., Reeves, P. J., Stephens, S., Winson, M. K., Salmond, G. P. C., Stewart, G. S. A. B., and Williams, P. 1993 The lux autoinducer regulates the production of exoenzyme virulence determinants in Erwinia carotovora and Pseudomonas aeruginosa. EMBO J. 12:2477-2482.

Kao, C. C., Barlow, E., and Sequeira, L. 1992. Extracellular polysaccharide is required for wild type virulence of Pseudomonas solanacearum. J. Bacteriol. 174:1068-1071.

Keen, N. T., Sims, J. J., Midland, S., Yoder, M., Jurnak, F., Shen, H., Boyd, C., Yucel, I., Lorang, J., and Murillo, J. 1993. Determinants of specificity in the interaction of plants with bacterial pathogens. Pages 211-220 in: Advances in Molecular Genetics of Plant-Microbe Interactions. Vol. 2. E. W. Nester and D. P. S. Verma, eds. Kluwer Academic Pub., Dordrecht, The Netherlands.

Kuan, T.-L., Minsavage, G. V., and Schaad, N. W. 1986. Aerial dispersal of Xanthomonas campestris pv. campestris from naturally infected Brassica campestris. Plant Dis. 70:409-413.

Leben, C. 1963. Multiplication of Xanthomonas vesicatoria on tomato seedlings. Phytopathology 53:778-781.

Leben, C. 1981. How plant-pathogenic bacteria survive. Plant Dis. 65: 633-637.

Leyns, F., DeCleene, M., Swings, J. G., and Deley, J. 1984. The host range of the genus Xanthomonas. Bot. Rev. 50:308-356.

Lindow, S. E. 1991. Determinants of epiphytic fitness in bacteria. Pages 295-314 in: Microbial Ecology of Leaves. J. H. Andrews and S. S. Hirano, eds. Springer Verlag, New York.

Pirhonen, M., Flego, D., Heikinheimo, R., and Palva, E. T. 1993. A small diffusible signal molecule is responsible for the global control of virulence and exoenzyme production in the plant pathogen Erwinia carotovora. EMBO J. 12:2467-2476.

Poplawsky, A. R., Kawalek, M. D., and Schaad, N. W. 1993. A xanthomonadin-encoding gene cluster for the identification of pathovars of Xanthomonas campestris. Mol. Plant-Microbe Interact. 6:545-552.

Poplawsky, A. R., and Chun, W. 1995. Strains of Xanthomonas campestris pv. campestris with atypical pigmentation isolated from commercial crucifer seeds. Plant Dis. 79:1021-1024.

Poplawsky, A. R., and Chun, W. 1997a. pigB determines a diffusible factor needed for EPS and xanthomonadin production in Xanthomonas campestris pv. campestris. J. Bacteriol. 179:439-444.

Poplawsky, A. R., and Chun, W. 1997b. Regulation of epiphytic fitness factor production in Xanthomonas campestris pv. campestris. (Abstr.) Phytopathology 87:S79

Poplawsky, A. R., Chun, W., Slater, H., Daniels, M. J., and Dow, J. M. 1998. Synthesis of extracellular polysaccharide, extracellular enzymes, and xanthomonadin in Xanthomonas campestris: Evidence for the involvement of two intercellular regulatory signals. Mol. PlantMicrobe Interact. 11:68-70.

Roberson, E. B., and Firestone, M. K. 1992. Relationship between desiccation and exopolysaccharide production in a soil Pseudomonas sp. Appl. Environ. Microbiol. 58:1284-1291.

Russell, H. L. 1898. A bacterial rot of cabbage and allied plants. Pages 130-134 in: Univ. Wis. Agric. Exp. Stn. Bull. No. 65.

Schaad, N. W. 1989. Detection of Xanthomonas campestris pv. campestris in crucifers. Pages 68-75 in: Detection of Bacteria in Seed and Other Planting Material. A. W. Saettler, N. W. Schaad, and D. A. Roth, eds. American Phytopathological Society, St. Paul MN 
Schaad, N. W., and Kendrick, R. 1975. A qualitative method for detecting Xanthomonas campestris in crucifer seed. Phytopathology 65: 1034-1036.

Schaad, N. W., and Stall, R. E. 1988. Xanthomonas. Pages 81-94 in: Laboratory Guide for Identification of Plant Pathogenic Bacteria. 2nd ed. N. W. Schaad, ed. American Phytopathological Society, St. Paul, MN.

Shaw, J. J., Settles, L. G., and Kado, C. I. 1988. Transposon Tn4431 mutagenesis of Xanthomonas campestris pv. campestris: Characterization of a nonpathogenic mutant and cloning of a locus for pathogenicity. Mol. Plant-Microbe Interact. 1:39-45.

Stachel, S. E., An, G., Flores, C., and Nester, E. W. 1985. A Tn3 LacZ transposon for the random generation of beta-galactosidase gene fusions: Application to the analysis of gene expression in Agrobacterium. EMBO J. 4:891-898.

Starr, M. P. 1981. The genus Xanthomonas. Pages 742-763 in: The Prokaryotes. Vol. I. M. P. Starr, H. Stolp, H. G. Truper, A Balows, and H. G. Schlegel, eds. Springer Verlag, Berlin.

Staub, T., and Williams, P. H. 1972. Factors influencing black rot lesion development in resistant and susceptible cabbage. Phytopathology 62: 722-728.

Sutton, J. C., and Williams, P. H. 1970a. Relation of xylem plugging to black rot lesion development in cabbage. Can. J. Bot. 48:391-401.
Sutton, J. C., and Williams, P. H. 1970b. Comparison of extracellular polysaccharide of Xanthomonas campestris from culture and from infected cabbage leaves. Can. J. Bot. 48:645-651.

Tang, J.-L., Liu, Y.-N., Barber, C. E., Dow, J. M., Wootton, J. C., and Daniels, M. J. 1991. Genetic and molecular analysis of a cluster of $r p f$ genes involved in positive regulation of synthesis of extracellular enzymes and polysaccharide in Xanthomonas campestris pv. campestris. Mol. Gen. Genet. 226:409-417.

Timmer, L. W., Marois, J. J., and Achor, D. 1987. Growth and survival of xanthomonads under conditions nonconducive to disease development. Phytopathology 77:1341-1345.

Turner, P., Barber, C., and Daniels, M. 1984. Behaviour of the transposons Tn5 and Tn7 in Xanthomonas campestris pv. campestris. Mol. Gen. Genet. 195:101-107.

Tuveson, R. W., Larson, R. A., and Kagan, J. 1988. Role of cloned carotenoid genes expressed in Escherichia coli in protecting against inactivation by near UV light and specific phototoxic molecules. J. Bacteriol. 170:4675-4680.

Wilkinson, J. F. 1958. The extracellular polysaccharides of bacteria. Bacteriol. Rev. 22:46-73.

Yanisch-Perron, C., Vieira, J., and Messing, J. 1985. Improved M13 phage cloning vectors and host strains: Nucleotide sequences of the M13mp18 and pUC19 vectors. Gene 33:103-111. 